\title{
AGRUPAMENTOS DE RESPONSABILIDADE CORPORATIVA: A PERCEPÇÃO DE STAKEHOLDERS SOBRE O ARRANJO PRODUTIVO LOCAL DE CONFECÇÕES DO AGRESTE PERNAMBUCANO ${ }^{1}$
}

\author{
GROUPINGS OF CORPORATE RESPONSIBILITY: PERCEPTIONS OF \\ STAKEHOLDERS ON THE LOCAL PRODUCTIVE ARRANGEMENT OF \\ CONFECTIONS OF AGRESTE PERNAMBUCANO
}

\author{
Claudinete de Fátima Silva Oliveira Santos ${ }^{2}$ \\ Carla Regina Pasa Gómez ${ }^{3}$
}

\begin{abstract}
RESUMO: Os Arranjos Produtivos Locais (APLs) são estratégias inovadoras de desenvolvimento local, integradora de espaços e redes sociais. Neles, os stakeholders interagem para atender as expectativas sociais, tornando visíveis suas ações de Responsabilidade Social Empresarial (RSE). O objetivo desse artigo é identificar em que estágio de Agrupamentos de Responsabilidade Corporativa adaptado de Zadec et al. (2003) pelo Instituto Ethos (2003), encontra-se o APL de Confecções do Agreste Pernambucano, conforme seus stakeholders. Apresenta-se uma revisão de: APLs, Teoria dos Stakeholders e Agrupamentos de Responsabilidade Corporativa. Esse estudo de caso qualitativo teve como instrumentos de coleta de dados: levantamento bibliográfico e documental, entrevista semi-estruturada e observação direta. Os resultados mostraram que o APL estudado está no estágio de Agrupamentos Formadores de Mercado pelo fortalecimento das interações entre atores e preocupação com a sustentabilidade de produtos, processos e negócios.
\end{abstract}

PALAVRAS-CHAVE: APL, stakeholders, RSE, Agrupamentos de Responsabilidade Corporativa, legitimidade e produtividade.

\begin{abstract}
Local Productive Arrangements (Arranjos Produtivos Locais - APLs) are innovative strategies of local development, integrator of places and social networks. At them, the stakeholders interact to attend the social expectations, turning their actions of Social-Business Responsibility (Responsabilidade Social Empresarial - RSE) visible. The aim of this article is identify in which stage of Groups of Corporative Responsibility adapted from Zadec et al. (2003) by Ethos Institute (2003), is the Local Productive Arrangement (APL) of Clothing of Pernambucan Agreste, according to their Stakeholders. It is presented a review for: APLs, Stakeholders Theory and Groups of Corporative Responsibility. This study of qualitative case had as instruments of data collecting: bibliographic and documental survey, semi-structured interview and direct observation. Results presented that the studied APL is in the stage of Groups of Market Formers by the strengthening of interactions between both actors and preoccupation of products sustainability, processes and business.
\end{abstract}

KEYWORDS: APL; Stakeholders; RSE; Groups of Corporative Responsibility; Legitimacy; Productiveness.

\footnotetext{
${ }^{1}$ Artigo Recebido em 06.10.2010. Revisado por pares em 03.11.2010. Recomendado em 28.04.2011 por Leomar dos Santos Editor. Publicado em 25.07.2011.

Organização Responsável pelo periódico: Universidade regional de Blumenau - FURB - www.furb.br/rn
}

\footnotetext{
${ }^{2}$ Universidade Federal de Pernambuco - UFP - claudineteosantos@hotmail.com

${ }^{3}$ Universidade Federal de Pernambuco - UFP - carlapasa@hotmail.com
} 


\section{INTRODUÇÃO}

Muito além da eficiência no crescimento econômico, o desenvolvimento - quer seja endógeno, humano ou local - deve primar pela elevação da qualidade de vida e da equidade social, e pela conservação ambiental - condição necessária à sustentabilidade entre gerações. Além disso, está engendrado no dinamismo econômico local, pela sua capacidade de mobilização sociocultural, tecnológica e política de recursos humanos, materiais e institucionais, e depende da estruturação e mobilização dos atores sociais locais em explorar suas potencialidades e especificidades.

Os atores sociais, também chamados de stakeholders, estão inseridos numa rede de relacionamentos em que todos interagem e tentam influenciar seus pares mutuamente; onde surgem parcerias e alianças que são realizadas conforme os interesses individuais e coletivos. Entre esses stakeholders estão as Micro e Pequenas Empresas (MPEs) que são indutoras do desenvolvimento local, impulsionado por sistemas de inovação e desenvolvimento, dentre eles os agrupamentos produtivos, denominados Arranjos Produtivos Locais.

Com esforços realizados coletivamente, num tom de competição e cooperação em estruturas em rede, Arranjos Produtivos Locais são iniciativas estratégicas voltadas à sobrevivência dessas empresas à concorrência mercadológica num setor, obtendo vantagens competitivas duradouras a partir da redução das desigualdades sociais, dos processos de aprendizagem coletiva e dinâmica inovativa, tendo como pano de fundo o desenvolvimento local (PORTER, 1989; CASTANHAR, 2006).

As MPEs precisam se adaptar às expectativas socioeconômicas, políticas e ambientais da sociedade em áreas que até então não eram vistas como de sua responsabilidade, oriundas: da competitividade acirrada provocada pela globalização dos mercados; do comportamento mais exigente do consumidor; e da pressão governamental através de políticas públicas de regulamentação, por uma atuação mais transparente e com maior responsabilidade (OLIVEIRA, 2008).

Essas expectativas influenciam os participantes do Arranjo Produtivo Local a adotarem um comportamento mais responsável, diante da percepção de sua importância nos processos sociais, trazendo reflexão para todos sobre a sua função na sociedade, como devem se comportar nas relações com e entre os atores do APL, e como devem responder as demandas da sociedade. Nesse sentido, a Responsabilidade Social Empresarial surge como meio de resposta a essas demandas para um desenvolvimento local sustentável e sustentado.

No debate a cerca da RSE não existe consenso sobre sua definição tão pouco sobre os requisitos para que se possa considerar uma organização socialmente responsável ou os processos pelos quais as organizações de fato adotam essa postura em suas atividades e negócios. A RSE evoluiu da maximização dos lucros dos acionistas e proprietários e da filantropia social, para ações e relações empresariais beneficiando também outras partes interessadas como empregados, clientes e consumidores, comunidade, governo, sindicatos e etc. (BARBIERI e CAJAZEIRA, 2009).

Dentre os vários modelos que abordam a RSE tem-se o "Responsible Competitiveness - Corporate Responsibility Clusters in Action”, proposto por Zadec et al (2003) que evidencia duas necessidades prementes: o diálogo e envolvimento das partes interessadas para alinhar as ações empresariais aos valores da sociedade, e o apoio a estratégias nacionais de 
AGRUPAMENTOS DE RESPONSABILIDADE CORPORATIVA: A PERCEPÇÃO

DE STAKEHOLDERS SOBRE O ARRANJO PRODUTIVO LOCAL DE

CONFECÇÕES DO AGRESTE PERNAMBUCANO

competitividade como clusters. O Instituto Ethos (2003) traduz clusters como agrupamentos produtivos, essenciais à ampliação das práticas de Responsabilidade Corporativa, apresentando resultados tanto em competitividade quanto em desenvolvimento sustentável.

Tais agrupamentos produtivos podem ser identificados como Arranjos Produtivos Locais. Isso posto, o objetivo desse estudo é identificar em que estágio de Agrupamentos de Responsabilidade Corporativa adaptado de Zadec et al. (2003) pelo Instituto Ethos (2003), encontra-se o APL de Confecções do Agreste Pernambucano, conforme seus stakeholders locais.

Pretende-se compreender a RSE praticada nesse APL por meio da percepção de seus atores ou partes interessadas. Para tanto, faz-se necessária a contextualização: de Arranjos Produtivos Locais; da Responsabilidade Social Empresarial com os Agrupamentos de Responsabilidade Corporativa; e do APL de Confecções do Agreste Pernambucano como Agrupamento de Responsabilidade Social.

\section{REFERENCIAL TEÓRICO}

\subsection{Arranjos Produtivos Locais}

O desenvolvimento local includente, integrado e sustentável é uma estratégia inovadora que visa o desenvolvimento humano, possibilitando o surgimento de comunidades mais sustentáveis, capazes de suprir suas necessidades imediatas e de despertar suas vocações locais, desenvolvendo suas potencialidades específicas (SEBRAE, 2007). Além disso, o desenvolvimento local se dá através do fortalecimento das Micro e Pequenas Empresas (MPEs), geradoras de oportunidades de trabalho (BORGES FILHO, 2005).

Uma das estratégias de desenvolvimento que busca soluções específicas aos problemas particulares local-regionais são os agrupamentos produtivos, conhecidos como Arranjos Produtivos Locais, os quais são “conjuntos de agentes econômicos, políticos e sociais, localizados em um mesmo território, desenvolvendo atividades econômicas correlatas e que apresentam vínculos expressivos de produção, interação, cooperação e aprendizagem” (LASTRES e CASSIOLATO, 2005, p.01).

Mytelka e Farinelli (2000) entendem APLs como a concentração e interação de empresas de um setor ou cadeia produtiva, num determinado espaço geográfico, que buscam criar um ambiente favorável ao processo de inovação e geração de externalidades produtivas e tecnológicas e ao desenvolvimento da competitividade das firmas, em conjunto com as demais instituições de coordenação e suporte, como sindicatos e associações empresariais, órgãos governamentais, instituições de ensino e de pesquisa.

Além das interações entre os atores econômicos, políticos e sociais, públicos e privados, os APLs possuem caráter empreendedor e inovador a partir da concentração de MPEs que produzem atividades de forte especificidade local em decorrência do conhecimento tácito e aprendizado coletivo (OLIVEIRA, 2008).

Outro aspecto relevante nessa abordagem de APLs seria a revalorização da identidade sociocultural territorial, característica contemporânea do desenvolvimento local, pois retrata uma visão integradora de espaços, atores sociais, mercados e políticas públicas 
intervencionistas para o alcance da geração de riquezas com equidade, respeito à diversidade, solidariedade, justiça e inclusão social.

APLs podem ser caracterizados por sua capacidade de integração territorial, num esforço dinâmico e harmônico entre cooperação e competição, e pela busca de competitividade sistêmica (SAMPAIO et al., 2004). Além disso, são um processo de conhecimento da realidade, tomada e implementação de decisão organizacional, composto por vários atores que interagem para propor o seu desenvolvimento local, diante da influência e pressão mútuas e simultâneas entre ele e seus atores (que podem ser parte do APL ou não) (MACHADO FILHO, 2006), emergindo daí a necessidade de iniciativas de cooperação entre eles para objetivos coletivos e como forma de melhorar a compreensão sobre as dificuldades, limitações e anseios locais. Tem-se então, a recuperação e renovação das estruturas sociais por meio da interação dos seus atores e da RSE (DREHER et al., 2007).

A fim de que essas relações entre atores não sejam tão transitórias e possam se repetir, é necessária uma concepção empresarial inovadora das relações sociais, econômicas e políticas, estabelecidas entre empresa e sociedade, utilizando a Responsabilidade Social como estratégia de confiabilidade e compromisso com os stakeholders (FALCÃO et al., 2008).

\subsection{Responsabilidade Social Empresarial}

O debate a cerca da Responsabilidade Social das Empresas é corrente desde o seu surgimento, uma vez que a sociedade e suas instituições, como empresas e governo, são regidos por obrigações legais, bem-estar social e justiça. Seu objetivo de estudo é entender não só os impactos econômicos, mas também, os impactos sociais, ambientais e políticos das atividades das empresas e como estas e a sociedade respondem a eles (OLIVEIRA, 2008).

Uma das definições mais utilizadas é a do Instituto Ethos que afirma ser a RSE

\footnotetext{
a forma de gestão que se define pela relação ética e transparente da empresa com todos os públicos com os quais ela se relaciona e pelo estabelecimento de metas empresariais compatíveis com o desenvolvimento sustentável da sociedade, preservando recursos ambientais e culturais para as gerações futuras, respeitando a diversidade e promovendo a redução das desigualdades sociais (INSTITUTO ETHOS, 2009, n.p.).
}

Muitas expressões são usadas de forma análoga, de acordo com suas necessidades e aplicabilidades, como é o caso da RSE e da Responsabilidade Social Corporativa (RSC). A RSE está contextualizada de maneira mais abrangente, nas ações integradas à promoção das necessidades e expectativas humanas, como proteção ao meio ambiente e ao social, consideradas transformadoras (NASCIMENTO et al., 2008). Como seu caso particular e sendo entendida como seu termo semelhante, a RSC se refere à responsabilidade social praticada pelas empresas constituídas de sociedades anônimas de capital aberto, onde a propriedade e a administração estão separadas (BARBIERI e CAJAZEIRA, 2009).

\subsection{Teoria dos Stakeholders}

A RSE sofreu sua expansão para além da relação entre acionista e dirigente, a partir do reconhecimento de outras partes interessadas nas suas ações. Essa visão sistêmica dá ênfase ao ambiente da empresa, entendendo sua constituição a partir de diferentes segmentos da 
AGRUPAMENTOS DE RESPONSABILIDADE CORPORATIVA: A PERCEPÇÃO

DE STAKEHOLDERS SOBRE O ARRANJO PRODUTIVO LOCAL DE

CONFECÇÕES DO AGRESTE PERNAMBUCANO

sociedade com expectativas e interesses próprios, que devem ser identificados por seus dirigentes para adequar suas respostas (BARBIERI e CAJAZEIRA, 2009).

Por serem avaliadas pelo conjunto de seus interessados, as empresas passam a estar mais atentas a sua interação com eles e com a sociedade. Desta forma, a análise das interrelações entre a empresa e seus stakeholders foram integradas por muitos autores ao desempenho econômico (FREEMAN, 1984; CARROLL, 1991; MACHADO FILHO, 2006).

Conforme Freeman (1984, p.25), stakeholder é “qualquer grupo ou indivíduo que pode afetar ou ser afetado pela realização de objetivos da empresa”. Clarkson (1995) entende que são pessoas ou grupos que possuem algum tipo de reivindicação, propriedade, direito ou interesse numa corporação e em suas atividades num determinado período.

Considerados partes legítimas interessadas no funcionamento da empresa, seja porque impactam ou são impactados por ela, ou simplesmente têm interesse no seu comportamento, os stakeholders são capazes de influenciar e serem influenciados pelos seus resultados estratégicos alcançados, possuindo reivindicações a respeito do seu desempenho organizacional (NASCIMENTO et al., 2008; OLIVEIRA, 2008).

Para atender a certas expectativas da sociedade, as empresas devem trazer benefícios sociais alinhados aos ganhos econômicos, e baseada nesse pressuposto surge a teoria dos stakeholders cuja concepção é baseada na gestão estratégica organizacional dinâmica, apoiada nos princípio da ética (FREEMAN, 1984; MITCHELL et al., 1997; FREEMAN e PHILIPS, 2002). Essa teoria entende que existe uma dependência entre o sucesso organizacional e a maneira como são geridas as relações com seus principais grupos de partes interessadas e/ou afetadas, como clientes, funcionários, fornecedores, comunidade, dentre outros.

Clarkson (1995) classifica os grupos de interesse em primários e secundários e entende a empresa como um sistema primário de grupos interessados, reunidos num conjunto complexo de relações intergrupais com direitos, objetivos, expectativas e responsabilidades distintas. Os grupos primários ou prioritários de interesse são aqueles cuja participação contínua é fundamental à sobrevivência da organização, evidenciando um alto grau de dependência da empresa para com esses stakeholders. Normalmente são constituídos pelos proprietários/acionistas (stockholders), investidores, empregados, clientes, fornecedores, e públicos de interesse, fornecedores de infra-estrutura e mercado, composto pelo governo e comunidade (CARROLL, 1991; CLARKSON, 1995).

Clarkson (1995) completa a classificação dos stakeholders ao definir os grupos secundários de interesse como sendo os interessados ou afetados que não estão envolvidos nas operações empresariais, que não são essenciais à sua sobrevivência, e os danos que eles podem causar à imagem da organização podem ser considerados de baixo impacto. Esses grupos secundários podem fazer oposição às políticas praticadas pela organização voltadas à realização de suas próprias necessidades, como também, das políticas direcionadas às suas responsabilidades com seus grupos prioritários de interesse.

Barbieri e Cajazeira (2009) afirmam que a força dessa teoria reside na consideração de que as empresas são redes dinâmicas de relacionamentos complexos, diversificados e multidimensionais. Essas inter-relações são "vias de mão-dupla": a empresa deve buscar identificar e atender aos seus interessados mais relevantes, aqueles que geram ações/reações 
mais urgentes; e os interessados, por sua vez, identificam seus comportamento e relevância para o desenvolvimento local dos Arranjos Produtivos.

\subsection{Agrupamentos de Responsabilidade Corporativa}

O modelo do Instituto Ethos (2003) para Agrupamentos de Responsabilidade Corporativa (ARC) foi adaptado do estudo de Zadec et al. (2003) e traz como pontos principais o diálogo e envolvimento dos stakeholders para o alinhamento das ações empresariais e dos valores sociais, assim como, o apoio as estratégias competitivas nacionais e territoriais, como os Arranjos Produtivos Locais. Esses Arranjos são fonte de inovação e podendo a RSE estimulá-la, e dessa forma gerar maior competitividade.

Dessa forma, tal modelo busca ampliar a responsabilidade corporativa por meio da competitividade. Seu entendimento é que tais agrupamentos apresentam resultados voltados à competitividade e ao desenvolvimento sustentável, oriundos das inter-relações entre seus atores, como empresas, setor público, sociedade civil, comunidade e organizações nãogovernamentais (INSTITUTO ETHOS, 2003).

Essas relações de confronto são diversas em suas formas e tamanhos e, se estabilizam por meio de parcerias, regulamentos estatutários e incentivos fiscais. Ainda, tais agrupamentos podem se desenvolver através de intervenções de políticas públicas ativas que maximizem o desenvolvimento do aprendizado e da competência, e de formalização de normas de mercado, regulamentos e incentivos legais (INSTITUTO ETHOS, 2003).

Apoiada na relação responsabilidade corporativa e competitividade, a pesquisa de Zadec et al. (2003) identificou diversos tipos de estágios de desenvolvimento de ARC, conforme a figura 01. Tais estágios não seguem necessariamente o mesmo padrão de evolução, e sua dinâmica e seu comportamento mudam de acordo com o tipo de atividade econômica, dependendo se for indústria ou comércio (INSTITUTO ETHOS, 2003), assim como, com o desenvolvimento local ou territorial do Arranjo Produtivo.

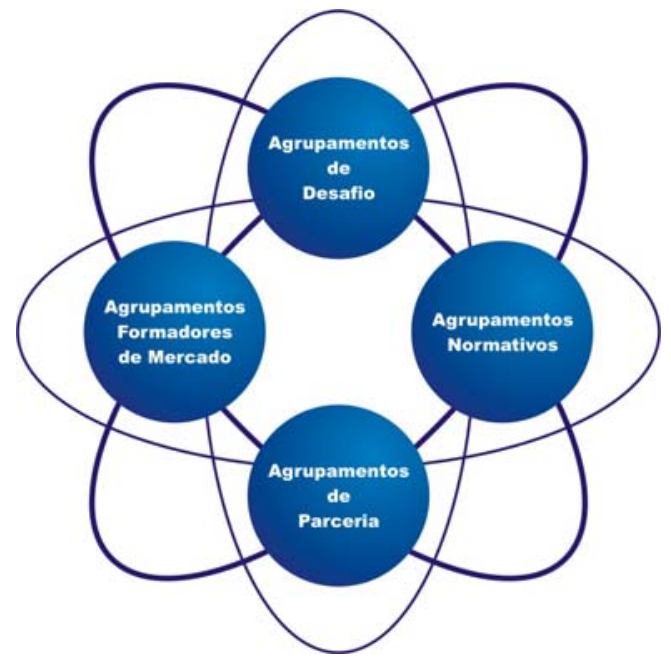

Figura 01: Agrupamentos de Responsabilidade Corporativa

Fonte: Traduzido de ZADEC et al. (2003, p.25).

Os Agrupamentos de Desafio "caracterizam-se pelas relações antagônicas entre seus participantes, formando no mínimo a base inicial para o desenvolvimento de vantagens 
AGRUPAMENTOS DE RESPONSABILIDADE CORPORATIVA: A PERCEPÇÃO

DE STAKEHOLDERS SOBRE O ARRANJO PRODUTIVO LOCAL DE

CONFECÇÕES DO AGRESTE PERNAMBUCANO

competitivas” (INSTITUTO ETHOS, 2003, p.07). Sua análise evidencia os atores indutores de ações ao desenvolvimento de suas capacidades de engajamento em processos complexos da sociedade e dessa forma, reforçar sua característica de formador de mercado dos agrupamentos, a seguir. Ainda, as empresas líderes em seu setor econômico tendem a apoiar o desenvolvimento e engajamento desses atores de forma regulamentar ou não.

Desse apoio, surgem com base na liderança, empresas que reformulam as condições competitivas por meio de características de interesse social e, de forma ampla, a sustentabilidade de seus produtos/serviços ou processos, numa evolução para Agrupamentos Formadores de Mercado (INSTITUTO ETHOS, 2003). Tais empresas líderes, que também podem estar entre as MPEs, mostram ao APL uma concepção inovadora através da impulsão do seu diferencial: o compromisso com os problemas sociais da sua localidade. Além disso, suas relações de rede com a sua cadeia de valor (fornecedores, câmaras setoriais, concorrentes) são valiosas e facilitam seu acesso ao mercado e à mão-de-obra locais.

Os Agrupamentos de Parcerias são oriundos do fortalecimento dessas relações a partir de parcerias multissetoriais formais as quais promovem vantagens competitivas, e visibilidade em iniciativas voltadas à conservação ambiental, aos padrões trabalhistas e à publicação de relatórios empresariais, que causam efeitos sobre a competitividade em toda a cadeia de valor por meio de maior alinhamento com padrões e práticas de responsabilidade corporativa (INSTITUTO ETHOS, 2003).

Por último, essas vantagens competitivas podem também serem advindas de iniciativas baseadas em políticas públicas, impositoras de medidas legais e fiscais, no intuito de melhorar os padrões e práticas de RSE. Essa evolução é denominada de Agrupamentos Normativos, nos quais as intervenções de políticas públicas possuem um papel relevante, com caráter prescritivo e facilitador do seu desenvolvimento (INSTITUTO ETHOS, 2003).

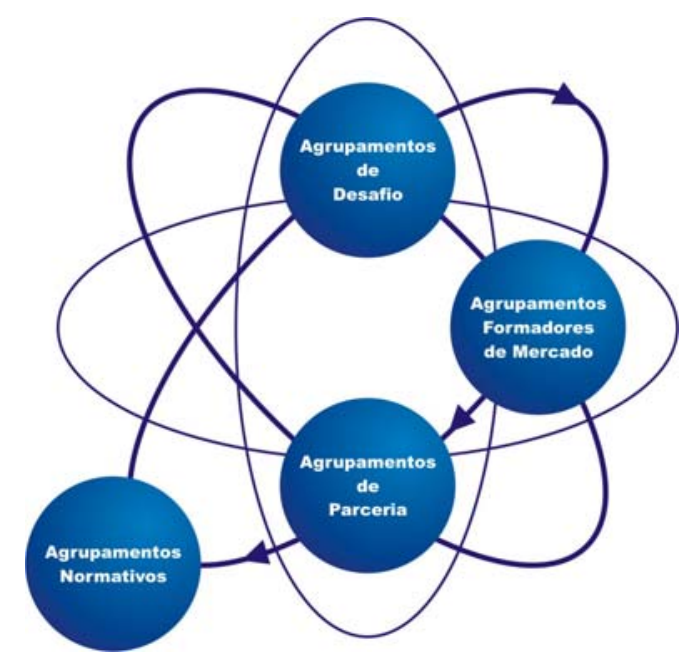

Figura 02: Sequência dos Agrupamentos

Fonte: Traduzido de ZADEC et al. (2003, p.34).

Zadec et al. (2003) entendem que existe uma sequência nos estágios, apresentada na figura 02, mas que não necessariamente precisa ser seguida pelos Agrupamentos, já que não são fenômenos estáticos nem distintos. Esses estágios raramente permanecem por períodos longos, e muitas vezes, combinam fatores que movimentam os clusters ou APLs, como 
legitimidade e produtividade, e direcionam suas políticas em diferentes fases do seu desenvolvimento.

Segundo o Instituto Ethos (2003, p.10), “os efeitos da legitimidade e da produtividade são essenciais para o desenvolvimento de agrupamentos de responsabilidade corporativa, bem como fatores de sucesso em determinados negócios”. Mesmo subestimados, esses efeitos são muito importantes, pois potencializam o sucesso das empresas quanto a sua competitividade local e nacional e transparência em atividades comerciais.

O feito da legitimidade é potencializado em agrupamentos quando há uma percepção dos interessados em relação aos impactos sociais e ambientais causados pela produção e distribuição na cadeia de valor. A aplicabilidade da legitimidade sobre os interessados é um fator crítico para determinar a força dos ARC, a qual depende do ramo de atividade, do estágio da percepção social dos atores e da habilidade e vontade do poder público local (ZADEC et al., 2003; INSTITUTO ETHOS, 2003).

O efeito da produtividade é potencializado em agrupamentos quando traduzido em práticas sociais e ambientais mais responsáveis, oriundas da eficiência dos recursos e ganhos de produção na cadeia de valor. Os fatores influenciadores são: redução de custos e riscos; pressão do setor financeiro; demonstração de sustentabilidade; governança corporativa; tecnologias de produção; competências internas; e rede de serviços externos (ZADEC et al., 2003; INSTITUTO ETHOS, 2003).

O potencial de legitimidade e produtividade para o surgimento de ARC pode variar de acordo com o setor econômico, no entanto as políticas públicas têm papel relevante na criação de condições para esse surgimento, assim como, para sua manutenção. Seu desafio é encorajar o desenvolvimento de inovações e maximizar seus benefícios para todo o agrupamento, mediante: setores específicos, acesso a mercados, barreiras comerciais e tensões por produtos socialmente responsáveis (INSTITUTO ETHOS, 2003).

O Instituto Ethos (2003) indica como diretrizes gerais para políticas públicas em ARC: determinar objetivos de desenvolvimento sustentável e metas sociais e comerciais mais localizadas; encorajar práticas amplas de RSE que favoreçam a competitividade; mapear o potencial para a criação desses agrupamentos; apoiá-los com a promoção de legislação e incentivos fiscais; e promover a eficiência nacional e internacional desses agrupamentos.

Os estágios de ARC demonstram características de Arranjos Produtivos Locais a partir das ações coletivas empreendidas por seus stakeholders, na busca do seu desenvolvimento territorial (de suas localidades pertencentes e comunidades circunvizinhas), da sua dinâmica produtiva e de mercado, e das políticas públicas reguladoras.

\section{PROCEDIMENTOS METODOLÓGICOS}

Essa pesquisa utiliza uma abordagem qualitativa, pois se preocupa em compreender e interpretar o APL de Confecções do Agreste Pernambucano, utilizando como tipologia de pesquisa a investigação exploratória e descritiva na identificação da percepção de alguns de seus stakeholders e das características relacionadas à RSE (MERRIAM, 1998).

Ainda, como estratégia de pesquisa, tem-se o estudo de caso por meio de pesquisa bibliográfica, documental e de campo (LIMA, 2004; YIN, 2005). O cruzamento das 
AGRUPAMENTOS DE RESPONSABILIDADE CORPORATIVA: A PERCEPÇÃO

DE STAKEHOLDERS SOBRE O ARRANJO PRODUTIVO LOCAL DE

CONFECÇÕES DO AGRESTE PERNAMBUCANO

informações levantadas serviu na identificação preliminar dos stakeholders do APL de Confecções a serem entrevistados. Conforme a orientação de Godoi e Mattos (2006) foi utilizada a abordagem "bola de neve" no inquérito dos entrevistados na identificação de outros que pertençam ao fenômeno estudado.

A saturação da construção do objeto teve como critério o julgamento nãoprobabilístico dos pesquisadores, baseado na seleção dos contextos, acessibilidade, fator tempo e recursos disponíveis, mesmo tendo a consciência de que isso não permite generalizações da investigação. A coleta de dados teve como instrumentos: a entrevista semiestruturada e a observação direta não-participante (MALHOTRA, 2001; PATTON, 2002).

As entrevistas foram realizadas nas principais cidades do APL de Confecções (Caruaru, Santa Cruz do Capibaribe e Toritama) com representantes de associações de classe, câmara setorial, centro de compras, poder público, serviço autônomo e sindicato que estão relacionados mais diretamente às empresas do APL. Para garantir a confidencialidade dos respondentes, optou-se pela utilização de pseudônimos durante a análise dos dados que são apresentados no quadro 01, com suas respectivas instituições.

As entrevistas seguiram um roteiro semi-estruturado com as seguintes categorias de análise: APL de Confecções do Agreste Pernambucano; Vantagens Competitivas; Desenvolvimento do APL; Interações entre Atores; Relações na Cadeia de Valor; Sustentabilidade de Produtos, Processos e Negócios; e Políticas Públicas. A seleção dessas categorias baseou-se no desenvolvimento do modelo de Zadec et al. (2003) e na sua adaptação para Agrupamentos de Responsabilidade Corporativa do Instituto Ethos (2003), discutida no referencial teórico desse trabalho.

\begin{tabular}{|l|l|l|}
\hline \multicolumn{1}{|c|}{ Pseudônimo } & \multicolumn{1}{|c|}{ Representante } & \multicolumn{1}{c|}{ Instituição Local } \\
\hline Entrevistado 01 & Consultor & $\begin{array}{l}\text { Associação de Comerciantes Industriais de } \\
\text { Caruaru (ACIC) }\end{array}$ \\
\hline Entrevistado 02 & Gerente Executivo & $\begin{array}{l}\text { Associação de Comerciantes Industriais de } \\
\text { Toritama (ACIT) }\end{array}$ \\
\hline Entrevistado 03 & Diretor de Marketing & $\begin{array}{l}\text { Associação de Confeccionistas de Santa } \\
\text { Cruz do Capibaribe (ASCAP) }\end{array}$ \\
\hline Entrevistado 04 & $\begin{array}{l}\text { Diretor de Desenvolvimento e } \\
\text { Empreendedorismo }\end{array}$ & $\begin{array}{l}\text { Câmara dos Diretores Lojistas (CDL) de } \\
\text { Santa Cruz do Capibaribe }\end{array}$ \\
\hline Entrevistado 05 & $\begin{array}{l}\text { Secretário Municipal de Indústria e } \\
\text { Comércio e empresário local }\end{array}$ & $\begin{array}{l}\text { Prefeitura Municipal de Toritama - } \\
\text { Secretaria de Indústria e Turismo }\end{array}$ \\
\hline Entrevistado 06 & $\begin{array}{l}\text { Coordenador de Gestão e Ex-secretário de } \\
\text { Defesa Social do Município de Toritama }\end{array}$ & $\begin{array}{l}\text { Centro de Comercialização Santa Cruz } \\
\text { Moda Center }\end{array}$ \\
\hline Entrevistado 07 & Consultor & $\begin{array}{l}\text { Serviço Brasileiro de Apoio à Micro e } \\
\text { Pequenas Empresas (SEBRAE) em Caruaru }\end{array}$ \\
\hline Entrevistado 08 & Gerente Regional & $\begin{array}{l}\text { Sindicato da Indústria do Vestuário de } \\
\text { Pernambuco (SINDVEST-PE) }\end{array}$ \\
\hline
\end{tabular}

Quadro 01: Pseudônimos, Representantes e Instituições Locais.

Fonte: As autoras.

A primeira categoria de análise faz breve apresentação do objeto de estudo. A segunda elenca na visão dos stakeholders entrevistados as Vantagens Competitivas do APL apresentado. A terceira trata do Desenvolvimento do APL a partir de seus problemas e das 
ações de cooperação entre atores para solucioná-los. A categoria Interações entre Atores discute as relações de cooperação e o fortalecimento de rede através da governança local.

Ainda, a categoria Relações na Cadeia de Valor trata de aspectos como o modo de produção operacionalizado pelas MPEs, assim como, a questão da informalidade. A próxima categoria: Sustentabilidade de Produtos, Processos e Negócios dá ênfase à questão ambiental direcionada ao beneficiamento do jeans e de projetos de atores voltados à sustentabilidade dos produtos e do negócio. E, por fim, a categoria de análise relacionada às Políticas Públicas de regulação e fiscalização no APL estudado.

A análise dos dados foi realizada pelo cruzamento dos achados: no levantamento documental, nos registros das observações e no conteúdo transcrito das entrevistas, de acordo com Bardin (1979). A seguir, serão apresentados a caracterização do lócus de estudo e os principais achados da pesquisa de campo e documental a partir das categorias de análise.

\section{ANÁLISE DE RESULTADOS}

\subsection{APL de Confecções do Agreste Pernambucano}

Conforme a composição de municípios adotada pelo GPT APL do MDIC ${ }^{1}$ (2008), e a sua localização geográfica, mediante a divisão por regiões do IBGE (2009), o APL de Confecções do Agreste Pernambucano situa-se na Mesorregião do Agreste Pernambucano, fazendo parte de quatro das suas seis microrregiões, a saber: Vale do Ipojuca, Alto Capibaribe, Médio Capibaribe e Brejo Pernambucano.

O IBGE (2009) esclarece a disposição dos municípios componentes nessas microrregiões: no Vale do Ipojuca localizam-se os municípios de Caruaru, Brejo da Madre de Deus, Belo Jardim e Pesqueira; no Alto Capibaribe situam-se as cidades de Toritama, Taquaritinga do Norte, Santa Cruz do Capibaribe e Surubim; no Médio Capibaribe a cidade de Passira; e no Brejo Pernambucano, Cupira.

Caruaru é considerada pelo GTP APL (2008) como a cidade pólo desse APL e juntamente com Santa Cruz do Capibaribe e Toritama formam o "triângulo das confecções" de Pernambuco, por serem suas cidades com maior movimentação de mercadorias e capital; a comercialização de confecções acontece nos parques de feiras de confecções e centros de compra nas três cidades.

Tais feiras surgiram inicialmente em Santa Cruz do Capibaribe - como uma alternativa de sobrevivência e de renda familiar - a partir da comercialização inicial de colchas (lençóis) e tapetes produzidos das "sobras” de malha tipo "helanca” oriundas das indústrias situadas no sul do país, dando origem assim ao seu nome, a feira da sulanca; a partir disso surge na década de 1960, o Pólo de Confecções com atuação forte no mercado de produtos populares de baixo custo (MESQUITA e ANDRADE, 2006).

O segmento de confecções tornou-se a principal atividade econômica desenvolvida em Santa Cruz do Capibaribe, com especialização em confecções em malha, e Toritama para diferenciar-se da concorrência da cidade vizinha, especializou-se em confecções em jeans (DIAS, 2007). O município de Toritama também merece especial destaque, pois produz 16\% da produção nacional de jeans (segunda maior produção do país), criando uma cadeia de 
AGRUPAMENTOS DE RESPONSABILIDADE CORPORATIVA: A PERCEPÇÃO

DE STAKEHOLDERS SOBRE O ARRANJO PRODUTIVO LOCAL DE

CONFECÇÕES DO AGRESTE PERNAMBUCANO

fábricas e lavanderias com geração de mais de 15 mil empregos diretos, com um faturamento anual de 453 milhões de reais (IBGE, 2007 apud Toritama PE, 2008).

Conhecida como a Capital do Agreste, Caruaru integrou o APL de Confecções a partir da década de 1980 e obtém seu desenvolvimento local por meio de outras atividades econômicas como comércio, artesanato, agropecuária, dentre elas (LIRA, 2006; DIAS, 2007), tendo como ponto central econômico as suas feiras livres: agropecuária, artesanato, calçados, produtos eletrônicos e confecções.

O APL de Confecções do Agreste Pernambucano, conta com 12 mil estabelecimentos, sendo que formais são 2.500 e informais 9.500, que geram 90 mil empregos diretos (MDIC, 2008), e pode ser considerado o segundo maior pólo de confecções do país, gerando $15 \%$ da produção de peças nacional, consumindo 270 mil toneladas de tecido por ano, e isso traz um faturamento de 2,8 milhões por ano ou 10\% do PIB de Pernambuco (ITEP, 2008).

\subsection{Vantagens Competitivas}

A criação do APL se deu através da necessidade de sobrevivência e da vocação natural para o empreendedorismo das pessoas das suas localidades. Essa vocação natural é enfatizada pelo Entrevistado 05, quando este aponta como diferencial competitivo “... a dinâmica desse povo... fabrica-se jeans na cidade [de Toritama], mas o melhor produto fabricado é o seu povo...”. O empreendedorismo local também é confirmado pelo representante do CDL Santa Cruz: “... diferencial é a cultura empreendedora, aquela coisa da idéia e de fazê-la se tornar realidade produtiva...”.

O empreendedorismo, a capacidade de adaptação e transformação, refletidos em sua flexibilidade, são vistos pelo representante do SEBRAE na dinâmica e predominância das MPEs, o que confere vantagens competitivas fortes. Aliada à flexibilidade, outro diferencial apresentado pelos Entrevistados 02 e 05, é a agilidade nos processos, tanto na confecção em malhas e jeans quanto na sua lavagem.

Outra vantagem citada pelos entrevistados é a quantidade de empresas no APL. Além de produzir variedade como nos lembra o representante do SEBRAE: “... a diversidade de oferta que vai da moda íntima ao jeans e tem de quase tudo... então, aquele que vem comprar aqui já sabe que aqui tem variedade...”, e confirma o Entrevistado 05: “... nós fabricamos jeans [em Toritama], Santa Cruz fabrica moda praia, moda íntima, uma diversidade... Caruaru também fabrica camisa, jeans...”, essas empresas trazem uma diversidade ou segmentação de produto crescente, aliada à qualidade, como nos relata o Entrevistado 03:

\footnotetext{
...em cada segmento na área de confecção, pode-se ter um diferencial... em geral, no comércio local, estão sendo os produtos de nível médio, que a qualidade está superando todas as expectativas... a cada dia nascem e crescem empresas de produto médio... até então só existia um produto popular...
}

Em pequenas fábricas ou células produtivas - consideradas por Dias (2007) como facções $^{2}$ de algumas de suas fases e relações de subcontratações - essas empresas interagem no processo produtivo de confecções em relações horizontais, substanciais à caracterização do APL, já que podem explorar ganhos coletivos de competitividade por meio de externalidades positivas. A partir do volume de produção e diversificação do produto, os empresários buscam caracterização da qualidade produtiva, como nos afirma o Entrevistado 06: 
...e hoje estão querendo descaracterizar a produção da cidade [Santa Cruz] como 'sulanca'... porque entendem que sulanca está relacionada à falta de qualidade, à improvisação... hoje querem falar de moda... dar mais qualidade... está se fomentando muito o turismo de negócios... por conta disso, começa a se trabalhar a questão da qualidade...

Os Entrevistados 06 e 08 concordam que o preço aliado à qualidade é um diferencial coletivo. Outras vantagens competitivas, como localização geográfica do APL e o crescimento do setor têxtil nacional foram mencionadas. Ainda, para o representante do SEBRAE, alguns mercados são exigentes quanto a práticas sociais e ambientalmente responsáveis e algumas empresas utilizam isso como diferencial competitivo.

\subsection{Desenvolvimento do APL}

As localidades formadoras do APL enfrentam, conforme o consenso dos entrevistados, problemas relacionados à infra-estrutura, como a ausência de: áreas de laser e convívio social; atividades culturais e de desporto; educação, saúde e segurança pública; saneamento; transporte, urbanização e pavimentação de vias urbanas e intermunicipais; e trade turístico.

Os problemas correlacionados pelos entrevistados ao APL de Confecções em si perpassam pela: carência de mão-de-obra qualificada para as diversas etapas de produção; ausência de distritos industriais em Santa Cruz do Capibaribe e Toritama e de distrito industrial específico para confecções e lavanderia de jeans em Caruaru; maior apoio do governo estadual; carência de uma menor alíquota tributária e linhas de crédito específicas para o setor; maior facilidade para formalização do empreendimento; distanciamento físico das agências de crédito, como o $\mathrm{BNB}^{3}$, sediado na capital do Estado; falta de qualidade das informações gerenciais; gestão ambiental principalmente relacionada ao tratamento dos resíduos e efluentes dos processos de beneficiamento (lavagem) do jeans, geralmente despejados em rios do território do APL; e ausência de outros setores econômicos na região o que acaba gerando a "monocultura da confecção".

A cultura da cooperação está sendo difundida no APL, existindo ações de desenvolvimento local, no entanto não apresentam uma formalidade e continuidade vistas em programas ou projetos. Algumas das iniciativas encontradas são de esforços individuais de algumas poucas empresas ou, mobilizadas localmente pelas associações de classe. O Entrevistado 06 citou como exemplo de iniciativa individual, a recente campanha social de combate às drogas que a empresa "Rota do Mar" de Santa Cruz do Capibaribe empreendeu.

Outros exemplos de mobilização através das associações dado pelos Entrevistados 01 e 02 são as: campanha de valorização da $\operatorname{ASPROMA}^{4}$ através da criação, pelos estilistas da Câmara dos Profissionais de Moda da ACIC, de modelos ecologicamente corretos através da incorporação de materiais reciclados; e a campanha do agasalho empreendida pela ACIT, em benefício de entidades filantrópicas. Nessas associações são discutidos os problemas e necessidades das localidades, assim como, da estrutura do APL, como nos relata o Entrevistado 04: “... é dentro desse âmbito de associativismo, que se discutem várias questões... aqui se discute tanto segurança pública até a estrutura produtiva...”.

\subsection{Interações entre Atores}


As relações entre os atores do APL de Confecções tendem a se tornar mais fortes e comprometidas com o desenvolvimento desse Arranjo através de uma Governança atuante e participativa. Isso é visto no depoimento do representante da ACIC quando relata que

\begin{abstract}
... as relações funcionam bem... a gente tem uma governança que funciona bem entre as cidades... as associações comerciais dessas cidades são muito unidas, são muito engajadas... começa-se a deixar de ter uma ação local pra ter uma mais regional... porque o fortalecimento - nós em Caruaru, Toritama, Santa Cruz e Surubim - é da região... se vende a imagem de um produto regional...
\end{abstract}

Mesmo sendo boas tais relações, ainda são esporádicas, como afirma o Entrevistado 02. Sua evolução tende a dissipar a cultura local de que o associativismo não gera vantagens ou do próprio bairrismo entre as cidades; na verdade, os atores começam a se engajarem a partir do seu empoderamento, como nos afirma o Entrevistado 07:

... [o associativismo] está mais articulado... o sindicato [SINDVEST-PE] está vindo
aqui... e ele se empodera que é um dos focos estratégicos do projeto: o
empoderamento dos atores, para que eles se sintam envolvidos a criar
sustentabilidade... os sindicatos e associações têm uns showrooms, a associação de
Caruaru tem a Rodada de Negócios, o SENAI é a parte de capacitação técnica, o
SEBRAE é a parte de gestão, existem os movimentos do Governo do Estado através
do ITEP ${ }^{6}$ na parte de lavanderia e esse com essa competência na parte ambiental...

Quanto às relações de cooperação, elas existem “... a partir do momento em que o empresário especificamente percebe o retorno... normalmente um retorno financeiro...”, como nos expõe o Entrevistado 07, o qual as exemplifica nas consultorias coletivas que o SEBRAE desenvolve, no intuito da diminuição de custos.

O mesmo grupo que participa dos eventos de divulgação e comercialização são também os representantes das instituições formadoras de um comitê gestor que está em sua fase embrionária, o qual está fortalecendo essa governança recente do APL. O Entrevistado 06 evidencia o interesse do Governo Municipal em articular essas relações de parceria e cooperação e o Entrevistado 05 revela o interesse do Governo do Estado:

... o governo do estado diferentemente dos outros anos, tomou a frente do planejamento estratégico com a governança do pólo... para os assuntos que interessam na questão de desenvolvimento sustentável... que isso antes era discutido durante muito tempo no próprio SEBRAE, que é um dos grandes parceiros, e que dirigiu esse planejamento estratégico... e agora, o maior interessado é o governo do estado...

Esse interesse do Governo Estadual reflete nas ações voltadas ao Fórum Estadual das Microempresas e Empresas de Pequeno Porte (MEPPs), comentado por vários entrevistados, que tem o intuito de transferir conhecimentos e competências em vários setores econômicos, inclusive aos APLs do Estado. Para o representante do SEBRAE, “... essa governança está sendo articulada de maneira sistemática em intervalos consideráveis para não criar uma coisa simplória que se desvalorize, mas ela é convocada quando se tem interesses em comum...”. Existem reuniões periódicas com os interessados para tratar dos gargalos e questões importantes à dinâmica do APL, e seu diálogo é intenso com troca de informações constantes.

\title{
4.5. Relações na Cadeia de Valor
}


A cadeia produtiva do APL de Confecções gira em torno de um aglomerado de MPEs beneficiadoras da matéria-prima (malha e jeans) e/ou de confecção (fabricação) propriamente dita. Em sua maioria, as empresas apenas confeccionam os produtos, mas algumas desempenham simultaneamente essas duas atividades. Tal APL é formado em sua maioria por empreendimentos informais de base familiar com a gestão do proprietário e grande participação dos membros da família na sua operacionalização (DIAS, 2007). Isso é confirmado pelo Entrevistado 04, “... a maioria das microempresas trabalham num ambiente amador... dentro de uma estrutura familiar...”. Outras empresas num ambiente melhor estruturado, pois:

... tem estilista próprio, com coleções próprias, planejando de forma mais expressiva,
um ano inteiro de produção... investindo em maquinário, em capacitação... investindo
em softwares... e não por coincidência são as que estão se destacando no cenário
estadual, nacional... elas têm começado a servir de espelho pra as outras... tudo isso
tem um custo... às vezes, tem-se um empreendedor com uma 'cabeça' melhor,
querendo implantar todas essas coisas, todas essas idéias, todos esses planos de
gestão, mas sobretudo existe uma limitação financeira...

A tendência de cooperação competitiva - terceirização e subcontratação - está presente no APL de Confecções do Agreste, como nos lembra o Entrevistado 07, de forma especializada, quando a empresa “... passa a produzir produto e desenvolver comercialização pela facção... essa facção hoje se vê mais em Toritama... essa produção é faccionada num que coloca o viés, outro o botão, outro que vai lavar... e já sai com a etiqueta do comprador...”. Além do faccionamento da produção, tem-se o faccionamento por nicho de mercado, onde a especialização é fornecer para redes de lojas: “... não se fabrica nada, vê-se lá [no nicho de mercado] o ponto e o produto, identificam-se facções aqui [no APL] e desenvolve produtos pra grandes lojas...”.

Uma questão bastante combatida nas entrevistas é a visão da informalidade como vantagem competitiva para o APL, como nos esclarece o Entrevistado 04: “... muitas pessoas colocam que a estrutura do pólo se desenvolve em função da sonegação de impostos, da informalidade...no entanto, vem crescendo em função da nossa estrutura tributária perversa...” Mas o que seria essa informalidade? No caso do APL de Confecções, é percebida pelos entrevistados como uma economia familiar informal, como relata o Entrevistado 05:

... essa informalidade é exatamente isso, o chefe da família compra o tecido, ele mesmo aprende a cortar e o corta... uma coisa meio que artesanal... então, temos os distribuidores de máquinas... e aí ele compra duas ou três máquinas... dividi-se esse valor a ser pago em meses, e ele vai trabalhar... então, ele vai costurar, a esposa vai costurar, o filho... é uma economia familiar informal... esses 'informais' de hoje são potenciais geradores de emprego no futuro...

O Entrevistado 07 identifica outro tipo de informalidade no APL, a contábil:

...essa informalidade faz com que apesar de se ter condições de comprar uma máquina de bordado de trezentos mil reais, oficialmente o faturamento está bem aquém disso, daí não se consegue empréstimo... o empreendedor se chateia e se frustra com o agente financeiro... mais isso está evoluindo cada vez mais...hoje isso é visto no próprio mercado... se o comprador é informal, vende-se informal... não se sente a importância de tirar a nota fiscal... mas a partir do momento em que o próprio 
comprador está vindo e ele é formal e sistemático e pede [a nota fiscal], então a contabilidade dele [do empresário] faz com que cresça e gere indiretamente outra necessidade: a contabilidade oficial...

Apesar da pouca representatividade dos fornecedores locais, as relações das empresas com os mesmos são diretas, conforme suas necessidades, não havendo um planejamento coletivo de compras de suprimento para atender aos públicos-alvo, descriminados pelo Entrevistado 03: “... trabalhamos para três públicos, também existe três ou mais tipos de fabricante... o público popular, aquele taxado de 'sulanca'... o médio que são as pessoas que compram o produto com certo valor agregado... e as que compram um produto de luxo...”.

\subsection{Sustentabilidade de Produtos, Processos e Negócios}

O principal problema relacionado à sustentabilidade dos processos é o gerenciamento dos resíduos produtivos, principalmente nas cidades que têm empresas de beneficiamento do jeans, como Toritama e Caruaru. Com o surgimento do Termo de Ajustamento de Conduta (TAC), as "lavanderias” passaram a ser mais cobradas pelo poder público e, com isso, houve uma busca pela profissionalização de seus processos, como revela os Entrevistados 02 e 05.

Segundo o representante do SEBRAE, existe no APL de Confecções do Agreste em torno de 150 lavanderias, e que essa quantidade maior de empresas acaba sendo um ponto negativo no gerenciamento desses resíduos produtivos, se comparado ao número menor de beneficiadoras em outros APLs, como o de Vestuário do Paraná que “... tem quatro, cinco, seis lavanderias muito grandes que tomam conta do mercado [de lavagem de jeans]... então, a maneira de gerenciar [dessas empresas paranaenses] esse resíduo é melhor aproveitada, pois seu crescimento é com foco num produto nacionalizado e não só em preço pra vender barato numa feira...”, seu foco é atender a um mercado diferenciado, mais exigente ambientalmente.

Corrobora com tal representante, o Entrevistado 03 ao afirmar que existe a preocupação ambiental de compradores

...geralmente quem tem essa preocupação, quem tenta não agredir o meio ambiente é
o pessoal que produz para o público médio e para o de luxo... as pessoas que
produzem o popular, que infelizmente são a maioria, e que trazem a maior
quantidade de renda pra cidade, preocupam-se exclusivamente com o produto e
preço...

Essa ausência de preocupação com a questão ambiental da maioria das empresas reflete também na falta de relatórios empresariais que tragam informações socioambientais aos interessados.

O SEBRAE trabalhou no APL alguns projetos voltados à sustentabilidade dos produtos e do negócio. Em relação ao produto, procurou fortalecer e melhorar a indústria de confecção local direcionando sua produção para outro nicho de mercado: o comprador profissional, pois como alertou seu representante: “... se fabricava peças e modelos, não se fabricava coleções e conceitos... agregar o design foi o grande esforço via associativismo...”.

Dentro desse projeto é trabalhada a auto-estima do empresário para que o conceito de origem negativa, de atitudes como “o que é bom é de fora, o que é daqui eu não visto”, fosse dissipado. Outro aspecto colocado pelo Entrevistado 07 é a diversificação e valorização dos produtos, desvinculando que 
... sulanca não é o produto, é um canal de comercialização que tem uma feira em determinado dia e que se vende um produto de menor valor agregado, mas existem produtos fabricados por empresas como a Iska Viva que já vendeu para a Espanha, que já participou de feiras internacionais...

Aliado a isso, outro projeto trabalhado é o comprador/vendedor, adaptado do modelo de exportação da $\mathrm{APEX}^{7}$, que visa trazer o comprador profissional, concentrado em São Paulo e Minas Gerais, às Rodadas de Negócios do APL, pagando despesas como passagens aéreas. Mais recentemente, de forma complementar estão sendo realizados showrooms ou Rodadas de Negócios itinerantes, no estado dos compradores para que estes percebam a qualidade dos produtos ofertados e entendam a vinda ao APL como um investimento.

\subsection{Políticas Públicas}

Inicialmente, as políticas públicas estaduais foram brandas quanto ao APL de Confecções, principalmente no que se refere à fiscalização. Com a veiculação na mídia do problema ambiental relacionado ao despejo de resíduos produtivos das lavanderias de jeans no principal rio do Estado, o Capibaribe, o Ministério Público agiu de maneira enérgica, como nos contou o Entrevistado 02, viabilizando o TAC; além disso, a fiscalização passou a ser mais rigorosa através de órgãos públicos, como relata o Entrevistado 07: “... a área ambiental é bem fiscalizada, até mais fiscalizada que no Sul [do país]... tem coisa que lá é autorizado e aqui não... a $\mathrm{CPRH}^{8}$ é muito exigente...”.

O SEBRAE e o ITEP, através de projetos ambientais voltados ao beneficiamento do jeans, conjuntamente com outros parceiros, buscam uma fiscalização mais educativa, tendo como objetivo a normalização das empresas. O ITEP possui vários projetos voltados ao APL de Confecções, como o "APROLAV" ou lavanderia experimental; o "Lavar sem Sujar" que capacita e conscientiza os empresários à importância da gestão ambiental; e, o "Programa de Apoio à Competitividade dos APLs de Pernambuco”, dentre outros (ITEP, 2008).

Os incentivos por parte dos governos estaduais e federais também são políticas públicas que beneficiam o APL, a exemplo tem-se a disponibilização de recursos e incentivos como: a atuação do próprio ITEP, a implantação dos Campus Caruaru da Universidade Federal de Pernambuco e da Universidade de Pernambuco, a duplicação da BR 232 e da BR 104, e as futuras instalações de distritos industriais nas principais localidades do APL. Os Entrevistados 06 e 07 nos esclarecem que com essas participações mais atuantes no desenvolvimento do APL de Confecções, o poder público perde sua neutralidade diante dos outros stakeholders, usando tais incentivos e benefícios como condição indireta para uma fiscalização mais latente nas empresas desse APL.

\section{CONSIDERAÇÕES FINAIS}

Os fenômenos de Agrupamentos de Responsabilidade Corporativa são dinâmicos e podem combinar fatores em diferentes níveis de atuação, como legitimidade e produtividade, entre seus estágios seqüenciais distintos. Dentre esses estágios seqüenciais, o APL de Confecções do Agreste Pernambucano passou pelo Agrupamento de Desafio, uma vez que suas relações de base deixaram de ser antagônicas, para se tornarem mais consolidadas. Os 
AGRUPAMENTOS DE RESPONSABILIDADE CORPORATIVA: A PERCEPÇÃO

DE STAKEHOLDERS SOBRE O ARRANJO PRODUTIVO LOCAL DE

CONFECÇÕES DO AGRESTE PERNAMBUCANO

stakeholders locais perceberam que precisam fortalecer essas inter-relações por meio de uma governança local para obter competitividade nacional.

Esse efeito da legitimidade está presente nas ações socioeconômicas desses líderes, que fazem parte da governança e, simultaneamente, são destaque no desenvolvimento local desse Arranjo Produtivo, atuando, muitas vezes, como empresários, administradores públicos, e gestores das associações e câmaras setoriais. Em resposta à pressão governamental e até ao pleito das comunidades, as empresas beneficiadoras de jeans, buscam processos produtivos mais sustentáveis, evidenciando certa preocupação ambiental.

A sustentabilidade de produtos e negócios está sendo trabalhada conforme o público comprador e as exigências de mercado. Estas últimas, são tratadas por algumas empresas do APL que possuem uma melhor estrutura organizacional; que podem servir de modelo inovador para as demais. Mesmo mostrando o efeito da produtividade na questão da sustentabilidade, as empresas do APL não apresentam aos seus stakeholders relatórios empresariais que mostrem seus investimentos socioambientais.

Diante disso, o APL de Confecções encontra-se entre os Agrupamentos Formadores de Mercado. No entanto, conforme o fortalecimento da governança se consolide a partir de parcerias multissetoriais formais, regulamentadas, e as empresas consigam um maior alinhamento de suas atividades produtivas com padrões e práticas de RSE, sua tendência natural é migrar para os Agrupamentos de Parcerias, segundo o Instituto Ethos (2003).

Quanto às intervenções de políticas públicas no APL, formadoras dos Agrupamentos Normativos, ainda estão no processo de fiscalização intensa e pouco incentivo de suas medidas legais voltado aos padrões e práticas de RSE e ao encorajamento de inovações coletivas. O que está em discussão entre os atores do comitê gestor do APL é a promoção de legislação tributária e de incentivos fiscais.

Essa pesquisa confirma o entendimento de Zadec et al. (2003) e do Instituto Ethos (2003) que os Agrupamentos de Responsabilidade Corporativa raramente se restringem a um dos quatro estágios identificados pelos autores. Isso é evidente especialmente no APL de Confecções do Agreste Pernambucano, que mesmo tendo sua predominância no estágio de Agrupamentos Formadores de Mercado, também possui aspectos relacionados a outros formatos de desenvolvimento em ARC, como por exemplo nos Agrupamentos de Parcerias.

Esse trabalho teve como objetivo identificar em que estágio de Agrupamentos de Responsabilidade Corporativa adaptado de Zadec et al. (2003) pelo Instituto Ethos (2003), encontra-se o APL de Confecções do Agreste Pernambucano, conforme seus stakeholders locais, usando pesquisa bibliográfica e documental, entrevistas semi-estruturadas e observação direta. Sua limitação se deu pela carência de informações oficiais à composição de requisitos de análise frente à RSE do APL de Confecções estudado. Sugere-se como pesquisas futuras a continuação do estudo da RSE em tal APL, assim como, as relações de rede entre seus atores.

\section{REFERENNCIAS}

BARBIERI, José Carlos; CAJAZEIRA, Jorge Emanuel Reis. Responsabilidade social empresarial e empresa sustentável: da teoria à prática. São Paulo: Saraiva, 2009.

BARDIN, Laurence. Análise de Conteúdo. Lisboa: Edições 70, 1979. 
BORGES FILHO, Álvaro O. Estrutura de referência aplicada à gestão estratégica capaz de promover o desenvolvimento regional sustentável na região de Guarapuava-PR. 2005. 225 f. Tese (Doutorado em Engenharia de Produção). UFSC. Florianópolis.

CARROLL, Archie B. The pyramid of corporate social responsibility: toward the moral management of organizational stakeholders. Business Horizons, July-August 1991.

CASTANHAR, José Cesar. Arranjos produtivos locais como estratégia de interiorização da atividade econômica, com dinamismo e redução das desigualdades. In: FLEURY, Sônia. Democracia, descentralização e desenvolvimento: Brasil \& Espanha. Rio de Janeiro: Editora FGV, 2006.

CLARKSON, Max B. E. A stakeholder framework for analyzing and evaluating corporate social performance. Academy of Management Review, v.20, n.1, p.92-117, jan 1995.

DIAS, Robson F. C. Ações estratégicas e políticas públicas em Arranjos Produtivos Locais: o caso do pólo de confecções do Agreste Pernambucano, 2007. 128p. Dissertação (Mestrado em Engenharia de Produção) - Programa de Pós-graduação em Engenharia de Produção, UFPE, 2007.

DREHER, Marinalva T.; SOUZA, Vanessa F. de S.; ULLRICH, Danielle R.

Desenvolvimento local e responsabilidade social, rumo às ações intersetoriais na região de Blumenau. Revista Brasileira de Gestão e Desenvolvimento Regional, v. 3, n. 2, p.49-71, mai/ago 2007.

FALCÃO, M. C.; SANTOS, C. F. O.; GÓMEZ, C. R. P. A visibilidade dos stakeholders no terceiro setor e a responsabilidade sócio-ambiental empresarial. In: X ENGEMA - Encontro Nacional de Gestão Empresarial e Meio Ambiente, Anais..., 2008.

FREEMAN, R. Edward. Strategic management: a stakeholder approach. London: Pitman Publishing, 1984.

FREEMAN, R. Edward; PHILLIPS, Robert A. Stakeholder theory: a libertarian defense. Business Ethics Quarterly, v.12, n.3, p.331-349, 2002.

GODOI, Christiane K.; MATTOS, Pedro L. C. L. de. Análise de entrevistas não estruturada: da formalização à pragmática da linguagem. In: Pesquisa qualitativa em estudos organizacionais: paradigmas, estratégias e métodos. GODOI, C. K.; BANDEIRA-DEMELO, R.; SILVA, A. B. da.; (org). São Paulo: Saraiva, 2006.

IBGE. Divisão territorial do Brasil. Disponível em: < http://biblioteca.ibge.gov.br/ visualizacao/monografias/GEBIS\%20-\%20RJ/DTB1963.pdf>. Acesso em: jan 2009.

INSTITUTO ETHOS DE EMPRESAS E RESPOSANBILIDADE SOCIAL. Agrupamentos de responsabilidade corporativa: alavancando a responsabilidade corporativa para atingir benefícios competitivos nacionais. Instituto Ethos Reflexão, v.4, n.9, abril 2003.

. O que é RSE. Disponível em: <http://www1.ethos.org.br/EthosWeb/pt/29/o_que_e_ rse/o_que_e_rse.aspx>. Acesso em: jan 2009.

IPEA. Identificação, mapeamento e caracterização estrutural de Arranjos Produtivos Locais no Brasil. 2006. Disponível em: <http://www.ipea.gov.br/sites/000 /2/estudospesq/ apls/Relat_final_IPEA28fev07.pdf>. Acesso em: out 2008.

ITEP. INSTITUTO TECNOLÓGICO DE PERNAMBUCO. Ações do ITEP para o desenvolvimento local e regional. 2008. Disponível em: <http://www.sectma.pe.gov. 
AGRUPAMENTOS DE RESPONSABILIDADE CORPORATIVA: A PERCEPÇÃO

DE STAKEHOLDERS SOBRE O ARRANJO PRODUTIVO LOCAL DE

CONFECÇÕES DO AGRESTE PERNAMBUCANO

br/seties/arquivos/agrestecentral/AgresteCentralSetentrional\%20A\%C3\%A7\%C3\%B5es\%20I TEP.pdf>. Acesso em: jul 2009.

LASTRES, Helena M. M.; CASSIOLATO, José E. Glossário de arranjos e sistemas produtivos e inovativos locais. 5.rev. Rio de Janeiro: UFRJ/IE/REDESIST, 2005

LIMA, Manolita C. Tipos de pesquisa e técnicas de coleta de materiais - a pesquisa bibliográfica. In: . Monografia: a engenharia da produção acadêmica. São Paulo: Saraiva, 2004. p. 37-49.

LIRA, Sônia Maria. Os aglomerados de micro e pequenas indústrias de confecções do Agreste/PE: um espaço construído na luta pela sobrevivência. Revista de Geografia, v.23, n.1, 2006.

MACHADO FILHO, C. P. Responsabilidade social e governança: o debate e as implicações. São Paulo: Thomson Learning, 2006.

MALHOTRA, N. K. Pesquisa de marketing: uma orientação aplicada. 3.ed. Porto Alegre: Bookman, 2001.

MERRIAM, Sharan B. The design of qualitative research. In: Qualitative research and case study applications in education. 2. ed. San Francisco: Jossey-Bass, 1998.

MESQUITA, Giovana B.; ANDRADE, Ana Maria de. O desenvolvimento local de Caruaru via indústria de confecção: uma alternativa possível? Revista Interface dos Saberes, v. 6, n. 2, Caruaru, 2006.

MDIC. MINISTÉRIO DO DESENVOLVIMENTO, INDÚSTRIA e COMÉRCIO EXTERIOR. Levantamento institucional de APLs 2007-2008 - $\mathbf{1}^{\text {a }}$ etapa. 2008. Disponível em: <http://www.mdic.gov.br/arquivos/dwnl_1210773147.pdf>. Acesso em: set 2008.

MITCHELL, Ronald L.; AGLE, Bradley R.; WOOD, Donna J. Towards a theory of stakeholder identification and salience deifing the principle of who and what really counts. Academy of Management, v.22, n.4, p.853-886, Out 1997.

MYTELKA, L.; FARINELLI, F. Local clusters, innovation systems and sustained competitiveness. Maastricht, Netherlands: United Nations University, 2000.

NASCIMENTO, Luis F.; LEMOS, Ângela D. da Cunha; MELLO, Maria Celina A. de. Gestão socioambiental estratégica. Porto Alegre: Bookman, 2008.

OLIVEIRA, José Antônio Puppim de. Empresas na sociedade: sustentabilidade e responsabilidade social. Rio de Janeiro: Elsevier, 2008.

PATTON, Michael Quinn. Qualitative research \& evaluation methods. 3 ed. Thousand Oaks: SAGE, 2002. p. 259-332.

PORTER, MICHEL E. Vantagem competitiva: criando e sustentando um desempenho superior. Rio de Janeiro: Elsevier, 1989, $29^{\circ}$ edição.

SAMPAIO, Carlos A. C.; MANTOVANELI JR., Oklinger; PELLIN, Valdinho. Arranjo produtivo local como estratégia que promove o ecodesenvolvimento: análises das experiências de Bonito (MS), Lagoa de Ibiraquera (Garopaba e Imbituba) (SC), e Santa Rosa de Lima (SC). In: II Seminário Internacional sobre Desenvolvimento Regional, Anais..., Santa Cruz do Sul, 2004.

SEBRAE. SERVIÇO DE APOIO ÀS MICRO E PEQUENAS EMPRESAS. Desenvolva sua comunidade. 2007. Disponível em: <http://www.sebraemg.com.br/Geral/ Visualizador 
Conteudo.aspx?cod_areasuperior $=2 \&$ cod_areaconteudo $=1347 \&$ cod_pasta $=201 \&$ navegacao $=$ \%C3\%81REAS_DE_ATUA\%C3\%87\%C3\%83O/Setores_em_Foco/Desenvolva_sua_Comun idade>. Acesso em: mar 2009.

TORITAMA PE. Cidade de Toritama - PE. 2008. Disponível em: <http://toritamajeans.com/cidade-toritama-pe/>. Acesso em: set 2008.

YIN, Robert K. Estudo de caso: planejamento e métodos. $3^{\circ}$ ed. Porto alegre: Bookman, 2005.

ZADEC, Simon; SABAPATHY, John; DOSSING, Helle; SWIFT, Tracey. Responsible competitiveness: corporate responsibility clusters in action. Accountability \& The Copenhagen Centre, 2003.

\section{Notas}

${ }^{1}$ Grupo Permanente de Trabalho em Arranjo Produtivo Local do Ministério do Desenvolvimento, Indústria e Comércio Exterior do Brasil.

${ }^{2}$ Dias (2007) utiliza facção no sentido de divisão em grupos distintos.

${ }^{3}$ Banco do Nordeste Brasileiro.

${ }^{4}$ Associação dos Protetores do Meio Ambiente (Caruaru/Pernambuco).

${ }^{5}$ Serviço Nacional de Aprendizagem Industrial em Pernambuco.

${ }^{6}$ Instituto Tecnológico de Pernambuco.

${ }^{7}$ Agência Brasileira de Promoção de Exportações e Investimentos.

${ }^{8}$ Agência Estadual de Meio Ambiente e Recursos Hídricos de Pernambuco. 